\title{
Investigating the Use of Advanced Manufacturing Technologies in the Manufacturing Assembly Sector in a Small Developing Country
}

\author{
Nadine Sangster, Rondell Duke, Terrence Lalla, Prakash Persad, and Aaron Ameerali
}

\begin{abstract}
The market place of the 21st century is evolving into one of merging national markets, fragmented consumer markets, and rapidly changing product technologies and so the use of new technologies has become vital to the manufacturing industry for their survival and sustainability. This work focused on the assembly type industry in a small developing country and aimed at identifying the use of advanced manufacturing technologies and their impact on this sector of the industry. It was found that some technologies were being used and that they had improved the effectiveness of those companies. Some of the specific advantages highlighted were improved productivity and thus improved efficiency, improved flexibility, more consistency in the production and quality improvements in the products. It was however noted that there was still room for improvement. Some of the recommendations included benchmarking against international standards, the adoption of a "made in TT" campaign and the effective utilisation of the technologies to improve competitive advantages and strategies.
\end{abstract}

Index Terms-Advanced manufacturing technology (AMT), Trinidad and Tobago (TT), assembly sector.

\section{INTRODUCTION}

The manufacturing sector plays an important role in the economy of many countries. At present manufacturing organizations operate in increasingly difficult environments. Customers are demanding higher standards of performance, new entrants are disrupting established industry structures, and employees are requiring more satisfying work, broader career paths and better wages and conditions. Historically firms would focus on improving the efficiency of their production process and assembly operations within the confines of their own manufacturing plants, however since greater emphasis is now placed on customer satisfaction, change is necessary. Manufacturers have responded to the challenges in a variety of ways, including the use of advanced manufacturing technologies, which is emerging as an important vehicle in changing the entire manufacturing function to achieve manufacturing excellence.

In the past, manufacturing in Trinidad and Tobago was an insignificant sector in the economy, dwarfed by agriculture and oil, however, there has been a shift from oil to gas and this has presented opportunities for the

Manuscript received May 19, 2015; revised October 13, 2015.

Nadine Sangster, Rondell Duke, Prakash Persad, and Aaron Ameerali are with Design and Manufacturing Engineering, the University of Trinidad and Tobago, Boulder, O’Meara Industrial Estate, ARIMA, Trinidad and Tobago (e-mail: nadine.sangster@utt.edu.tt).

Terrence Lalla is with the Department of Mechanical and Manufacturing Engineering, the University of the West Indies, St Augustine Campus, Trinidad and Tobago (e-mail: terrence.lalla@sta.uwi.edu). manufacturing sector to flourish, particularly, downstream manufacturing. According to Advameg, Inc [1] approximately sixty five per cent of the gas produced by the National Gas Company in TT went towards producing ammonia and methanol which earned US \$248 million and US $\$ 148$ million respectively. During the previous year Trinidad and Tobago earned US \$206 million from steel exports, in which locally produced gas was use to fuel steel, cement and other manufacturing industries.

Of recent, the manufacturing sector experienced some of the toughest years in decades. Manufacturers were losing as much as fifty per cent of their sales and the need for a more competitive business environment was highlighted. The local economy slowed in tandem with the global slowdown, businesses sought to reduce their costs, scale back on new products, and refocus on core activities and products. The importance of a reduced dependence on oil and gas became even more apparent in the light of this global financial crisis, particularly since the prices of these commodities and the country's main source of income, remained volatile. Thus it was made clear that the manufacturing sector would have to achieve self-sustaining growth in order to mitigate the repercussions of the economic crisis.

Yamfwa [2] suggested that AMT investment along with manufacturing infrastructure resulted in better firm performance such as growth and profit, however, he noted that the use of AMTs might differ between developed countries and newly industrialized countries. Although the benefits appeared to be good, it is noted that the non-financial measures of performance could give a better description of what goes on during the production of goods than financial measures. As such this paper will attempt to understand the role of AMTs and its possible influence on manufacturing performance.

\section{LITERATURE REVIEW}

Advanced manufacturing technologies are defined as a broad spectrum of computer controlled automated process technologies [2]. This definition clearly states AMTs as a group of technologies but limits them to within process capabilities.

Dangayach and Deshmukh [3] classified AMT into direct, indirect and administrative technologies. According to the authors, direct AMT is a technology used on the factory floor to cut, join, reshape, transport, store or modify materials. Meanwhile, indirect AMT refers to the technology used to design products and schedule productions and administrative AMT refers to technology used to give administrative 
support to the factory and integrate its operations with the rest of the organization.

Idris et al. [4] and Kotha [5] classes the various manufacturing technologies into four groups, on the basis of imbedded information processing capabilities. These groups are Product design technologies (PDT), Process technologies (PT), Logistics planning technologies (LPT), Information exchange technologies (IET). Product design technologies include technologies such as CAD, computer-aided engineering (CAE), and automated drafting technologies that focus primarily on product definition, and design-related information processing functions. Process technologies include technologies such as, numerically controlled (NC) machines, and programmable controllers that focus on the process aspects of manufacturing. Logistics planning technologies focus on controlling and monitoring the material flow from the acquisition of raw materials to the delivery of finished products, and related counter flows of logistical information. It includes production scheduling systems, shop floor control systems and materials requirements planning. Information exchange technologies helps to facilitate the storage and exchange of information among the processes, products, and logistics technologies identified above. Technologies such as common databases, system translators, data transfer protocols, intra- and inter-factory networks belong to this group [5].

Abdul Ghani \& Jayabalan [6] explained that AMTs should be classified into three levels. AMT level one would consist of stand-alone machine tools or equipment that are controlled by self-contained computers. The purpose of level one is to use equipment that would replace conventional machine tools in manufacturing to achieve better quality, for example, by reducing rework, rejections, and down time. AMT level two would be manufacturing cells based on the grouping of machines to perform a variety of tasks to produce a family of parts. The objective of this type of production is to have new product mix in batches with high quality in response to change in needs of customers. In AMT level three, cells (in level two) are connected to form linked chains through a computerized information network. This level of AMT offers production facility that integrates two or more cells to achieve competitive advantages such as the rapid generation of new products and entry to new markets. Efficient utilization of advanced manufacturing technologies (AMTs) is considered a very important tool for manufacturers worldwide to maintain and strengthen their ability to compete on extremely competitive international markets. It widely understood that AMTs offer great potential to provide the respective companies with many tangible and intangible benefits [7]. Idris et al. [4] echoed similar sentiments but named the tangible benefits and also grouped them as easily quantifiable benefits, such as inventory savings, less floor space, improved return on investment (ROI) and reduced unit cost. They also described the intangible benefits as benefits which are difficult to quantify and this included an enhanced competitive advantage, increased flexibility, improved product quality and quick response to customer demand. Tracey et al. and Gouvea et al. [8], [9], also considered AMTs as a competitive weapon that could be used by enterprises seeking to improve their competiveness. These utopian benefits of AMTs however do not come automatically to those firms that implement them [10].

Zammuto and Gunawardana [11], [12]; and Kotha [5] expressed similar views indicating that investments in advanced manufacturing technologies alone are insufficient to obtain the potential benefits if the organization does not possess adaptive capabilities in other functional areas. According to Saberi \& Yusuff [13], to achieve the desired benefits, the structure and infrastructure of the organization must match to ensure that the implementation of technologies lead to the expected benefits. Therefore a framework that facilitates AMT adopters in determining the requirements of AMT adoption, with the right mix of strategic elements is needed. The authors also argue that the degree of fit between an organization's competitive priorities and its key decisions regarding its investments provides the key to developing the full potential of operations as a competitive weapon that would lead to quality, cost efficiency and flexibility at the same time. Dean and Snell, [14] also stated that the maximum benefits will accrue if there is a fit between AMTs employed by the firm and the firm strategies. This meant that AMT would be a major determinant of strategy and vice versa.

On the other hand AMT adoption often requires high levels of initial investment. The payback period is usually longer than traditional manufacturing technologies, which means that the investment may initially result in an increase in the cost of manufacturing [15] also the levels of risk associated with AMT implementation are generally higher versus traditional manufacturing technologies. The authors also stated that the level of risk would become even greater if the AMT adopter lacks the relevant experience concerning AMT evaluation and implementation. Saberi \& Yusuff [13] echoed similar sentiments stating that AMTs change the external risk propensity of a firm from risk adverse to risk prone. This would mean that management would have to do thorough preparations prior to AMT implementation. According to Ramamurthy and King [16], improper or inadequate planning for implementation of new technology has resulted in failures of AMT on account of human and organizational factors.

\section{METHOD}

For this work, a small survey was conducted via the use of a questionnaire and semi - structured interviews with staff at the factories. The questionnaire was administered to each company in the population via e-mail, or through semi structured interviews with the relevant personnel at these companies. The questionnaire examined specific population characteristics and was divided into five sections as follows:

1) Information about the Competitiveness of the Company

2) Information about the Competitive Advantage of the Company.

3) Information about the use of AMTs at the Company.

4) Information about the Impacts of AMTs on the Company.

5) Information about the Effectiveness of AMTs currently implemented at the Company.

There are twenty - seven (27) assembly type factories in TT and of those, six (6) companies indicated that they would 
not be able to participate in the study for varying reasons thus twenty-one (21) companies were surveyed. The staffs at these companies who filled in the questionnaire or were interviewed were general managers, production managers or production personnel.

\section{DAta AnAlysis And Results}

This section looks at the results from the questionnaires and interviews. The results shown below indicate answers for some of the main questions.

Question 1: Do you believe that AMTs have increased or can increase the competitiveness of your organization in the local manufacturing sector?

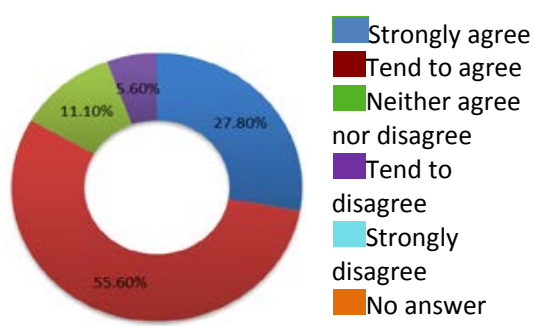

Fig.1. Showing the answer to question 1.

The responses, as shown in Fig. 1, revealed that $27.8 \%$ of the companies strongly agree that AMT has or can increase the competiveness of their organization in the local manufacturing sector. $55.6 \%$ tended to agree with the statement while $5.6 \%$ tended not to agree with the statement and $11.1 \%$ did not agree or disagree with the statement. It was observed that companies that enjoy 'near monopoly' status who indicated that there are no similar companies in Trinidad and Tobago could not determine the impact of AMTs on the competitiveness of their organizations in the local industry. Industries with high competition and readily available substitute products strongly agreed that the use of AMTs positively impacted their ability to compete in the local industry. Only one company did not use any form of AMT, tended to disagree that AMTs increased the competiveness of the company in the local sector.

Question 2: Do you believe that AMTs have increased or can increase the global competitiveness of your organization?

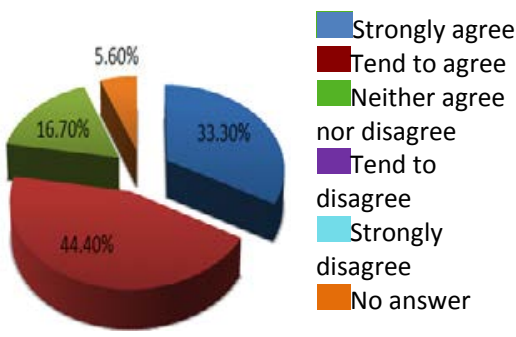

Fig. 2. Showing the answer to question 2.

When questioned whether they believed that AMTs could increase the global competitiveness of their organization $33.3 \%$ of the respondents strongly agreed, $44.4 \%$ tended to agree with the statement, $16.7 \%$ neither agreed nor disagreed with the statement and $5.6 \%$ of the respondents did not answer the question as shown in Fig. 2. As expected the companies who already exported their products strongly agreed with the literature and statement that AMTs may increase the global competitiveness of their company. A few companies, who do not trade beyond the Caribbean, neither agreed nor disagreed with the statement.

Question 3: Have AMTs resulted in growth for your organization?

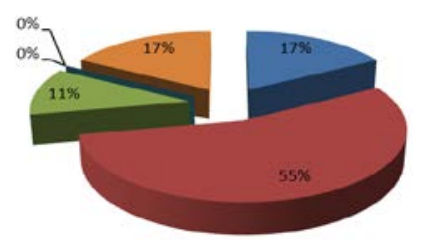

Fig. 3. Showing the answer to question 3.

$17 \%$ of the respondents strongly agreed that AMTs have resulted in growth for their organization. Also of interest is that $55 \%$ of them tended to agree that AMTs have resulted in growth for their organization while $11 \%$ neither agreed nor disagreed that AMTs have resulted in growth for their organization and $17 \%$ did not respond to this question. This is shown in Fig. 3.

Question 4: Has your company benefitted from the manufacturing incentives in the last budget?

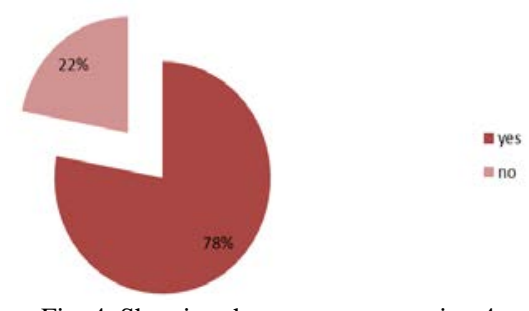

Fig. 4. Showing the answer to question 4.

$78 \%$ of the respondents indicated that their companies have not benefitted from the manufacturing incentives in the last budget and 22\% indicated that they have benefitted (shown in Fig. 4). It seems that many manufacturers were aware of the manufacturing incentives in the budget and as a result they did not capitalize on the incentives offered by the present Government of Trinidad and Tobago.

Question 5: What is your company's strategy for competing on a global scale?

The answers revealed that a number of strategies were being utilized by these companies to compete on a global scale. 5 companies are competing based on Quality, 5 others are competing based on Efficiency in Production and 3 companies indicate they use Customer Satisfaction. To a lesser extent at least one company utilized one of the following strategies Increased Productivity, Innovation, Government Assistance and Partnerships with foreign wholesalers.

Question 6: What is your company's market?

Data analysis has revealed that all the companies that took part in the study, target and supply the local market. 15 companies indicated that they also target regional markets, while only 3 companies target the South American market and 3 companies the Central American market in addition to the other markets they serve.

Many of the manufacturers also believed that AMTs could reduce operating costs, provide high levels of output by removing inconsistent human input, improve manufacturing flexibility and lead time to market, therefore they may provide the entire Assembly Type Sector with the ability to 
compete internationally way beyond our region.

Question 7: What is your company's competitive advantage? Does the implementation of advanced manufacturing technology help this?

12 of the respondents indicated that the implementation of AMTs help them to achieve and maintain their competitive advantage. 4 companies indicated that their competitive advantage is based on Quality, 2 companies indicated their competitive advantage relies on low cost production another 2 indicated their competitive advantage is based on Fast Service. At least one company identified one of the following as their competitive advantage Consistency, New Product Development, Convenience, Flexibility, Production Efficiency and Customization.

Question 8: Is this competitive advantage based on manufacturing techniques and equipment?

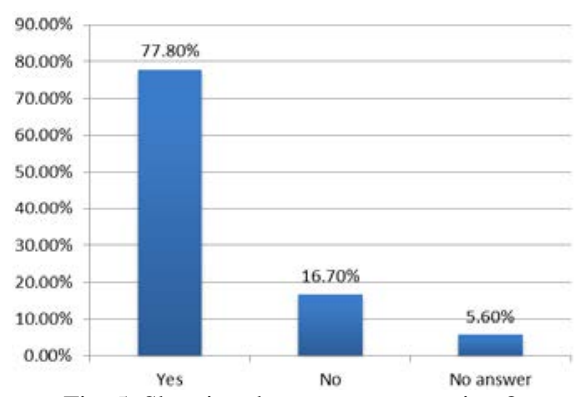

Fig. 5. Showing the answer to question 8.

$77.8 \%$ noted that their competitive advantage was based on their manufacturing techniques and equipment, $16.7 \%$ believed that their competitive advantage was not based on their manufacturing techniques and equipment (shown in Fig. 5). 5.6\% respondents did not give an answer to this question.

Question 9: Does this company use some form of Advanced Manufacturing Technology?

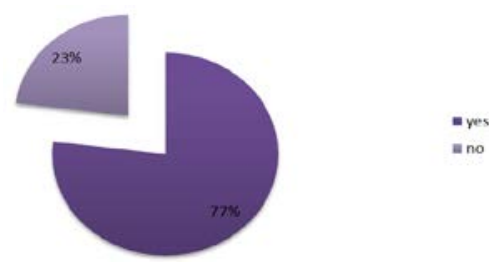

Fig. 6. Showing the answer to question 9.

Data analysis (Fig. 6) has revealed that $77 \%$ of the respondents indicated that their company use AMTs. 23\% indicated that their company does not use AMTs in their production process.

Question 10: What are the types of technologies are currently present in the plant?

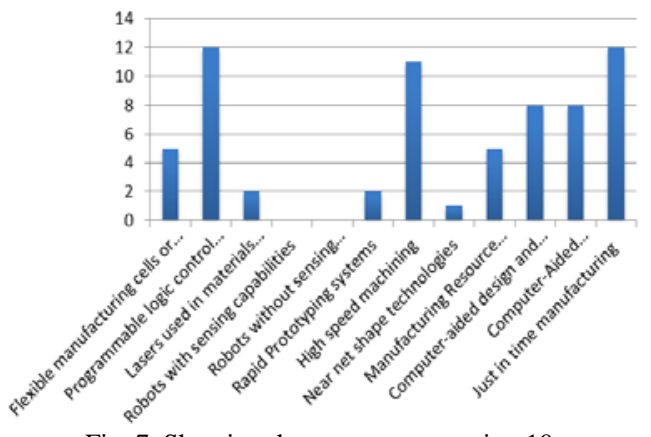

Fig. 7. Showing the answer to question 10.

It was observed that Programmable Logic Control
Machines or Processes (CNC and NC), Just in Time Manufacturing (JIT), High speed machining, Computer Aided Design (CAD), and Computer Aided Manufacturing (CAM) are the most common AMTs found in the Assembly Type Industry. To a lesser degree Flexible manufacturing cells or systems (FMC/FMS), Lasers used in material processing, Rapid prototyping, near net shape technologies and Manufacturing Resource Planning (MRP) were also present in the companies surveyed. This is shown in Fig. 7.

Question 11: For the technologies that are presently used, what are some of the advantages? Please state the specific advantage to each technology.

The main advantages observed were improved efficiency, experienced improved productivity, improved flexibility, more consistency in production and quality improvements in their products and the entire production process.

Other advantages observed were greater levels of customer satisfaction, accuracy in their production process, reductions in their lead times and lower labour cost.

To a lesser extent the following advantages were observed by at least one of the respondents - improved effectiveness, increased ability to innovate and better machine efficiency/ less down time.

Question 12: Are the employees willing to learn about new technologies?

$78 \%$ of the respondents indicated that the employees of their company were willing to learn about new technologies, while $22 \%$ of them indicated that employees in their company were not willing to learn about new technologies.

Question 13: Please identify the most intangible benefits of AMT achieved by your organization?

Eight (8) companies enjoyed increased job satisfaction among its employees, 2 others considered increased productivity as an intangible benefit. Increased flexibility and increased accuracy were enjoyed by at least one company respectively.

Some of the comments noted included:

- Increased morale and a happier workforce.

- Appreciation of new and growing use of technology in the first world and changes of culture and attitudes in the work environment.

Question 14: Do you believe that AMTs have contributed to the overall effectiveness of your organization?

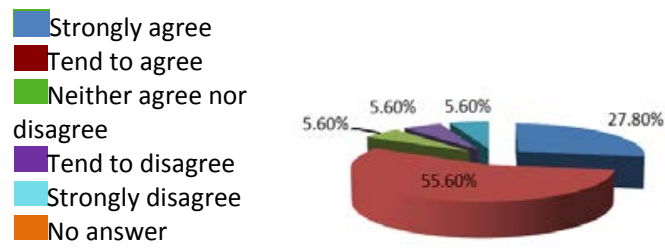

Fig. 8. Showing the answer to question 14

Fig. 8 above displays that $27.8 \%$ of the respondents strongly believed that AMTs have contributed to the overall effectiveness of their organization. 55.6\% tend to agree with the statement and 5.6\% neither agreed nor disagreed with the statement, additionally $5.6 \%$ tended to disagree with the statement and lastly a further $5.6 \%$ strongly disagreed with the statement.

Question 15: How is the effectiveness of AMTs currently used measured? 
$33.3 \%$ of the companies indicated that they measure the effectiveness of AMTs. Three (3) companies indicated that they use production reports to measure effectiveness, 3 also reported that they use financial statement analysis to measure effectiveness while 1 stipulated that they use customer satisfaction analysis to measure the effectiveness of their AMTs. Some special measures included "spoilage reports, out of specification reports, not in time reports, absenteeism, customer satisfaction reports, down time reports, line efficiency and sales reports.

\section{RECOMMENDATIONS}

The following could be recommended to the local manufacturers from the survey conducted.

\section{A. Strive to Be Globally Competitive}

Implementation and exploitation of AMTs may help companies in the local Assembly Type Industry to profitably manufacture and sell products that are designed to meet consumer's ever changing taste, international quality standards, at lower unit cost, and be internationally competitive and allow them to withstand competition in the local market and also to be competitively viable in foreign markets as well. Long gone are the days of closed markets due to increased trade liberalization, market fragmentation, changing consumer taste and purchasing methods. Therefore companies must be internationally competitive in order to survive in the modern manufacturing environment of the 21st century.

\section{B. Bench marking of Manufacturing Technologies}

The technologies that are being used in the Assembly Type sector of the leading manufacturing economies across the world should be investigated to determine if these technologies could be adapted and implemented in the local sector to ensure our manufacturers are on par with the best Assembly Type companies around the world. They should also be monitored and evaluated to determine what are the advantages and disadvantages achieved by AMTs in these economies. This may give local manufacturers in the Assembly Type Industry better awareness of the AMTs that exist, may help identify which AMTs get results, and also give them a sense of direction of where their manufacturing technology need to be in order to be internationally competitive.

\section{Establish a "Made in Trinidad and Tobago" Campaign}

The local Assembly Type Industry either individually or in collaboration with the Government should establish a buy local campaign in Trinidad and Tobago to ensure that the local Assembly Type Industry could withstand the devastating effects of foreign companies supplying the local consumers. The campaign should be centered on goods and services of the local Assembly Type Industry being produced. It should be stressed that they were made using the advanced manufacturing technologies resulting in high quality, well designed, differentiated, competitively priced products that are on par with the best Assembly Type Manufacturers worldwide or are of superior value and more convenient for locals to purchase.

A "Made in Trinidad and Tobago" campaign may also help foreign consumers identify products that are manufactured in Trinidad and Tobago and which may help to put the local Assembly Type Industry on the globe for being known to produce high quality, differentiated, competitively priced products and services, which may lead to increased demand and profits for goods and services produced in Trinidad and Tobago. The implementation and exploitation of AMTs may prove to be a valuable marketing tool that can be used by companies in the local Assembly Type Industry.

\section{AMTs should Be Used to Enhance the Ability of Production Staff}

The purpose of AMTs is to enhance rather than to replace the ability of production staff. New advanced technologies permit the advantages of machines to be effectively combined with human cognitive capabilities. It is in this area where advanced technology adoption appears to have had the greatest impact.

Staff, of companies in the assembly type industry, should be trained in the latest AMTs that their company implements. This study has revealed that production personnel in the companies that utilize AMTs have increased job satisfaction from the implementation of AMTs that reduced the amount of manual labour and repetitive jobs. The technologies also challenged them to learn and master new job related skills.

Cross-functional teams should be used in the development of new products and production methods. Employees that interact directly with consumers have rich knowledge of exactly what customers are asking for and what they want thus may be able to enrich the design stage of new product development process. Machine operators and production staff may have solutions about how to simplify the production process, and also on how to make it more efficient and effective. Therefore they should not be replaced by AMTs but trained on how to make the AMTs deliver the many benefits they can bring to companies that implement them.

\section{E. Utilize AMTs to Develop and Maintain Competitive Advantages and Strategies}

AMTs can provide distinctive competitive advantages in cost and process leadership. The modern manufacturing industry, which is characterized by intense global competition and rapid advancements of manufacturing technology, may require a shift in strategic business priorities towards quality, cost effectiveness and responsiveness to marketplace changes, by all the companies present in the local assembly type industry.

AMTs may help companies to improve their competitiveness through the development of distinct competitive advantages. Next generation manufacturers need to effectively integrate AMTs to gain a competitive advantage, reduce risk and improve productivity. An intangible benefit of AMTs is an enhanced competitive advantage.

AMTs need to be included in the development of short, medium and long-term strategic plans. AMTs impact not just manufacturing, but the whole business operations giving new challenges to a firm's ability to manage both manufacturing 
and information technologies. Therefore proper planning and attention should be given to AMTs by top management.

\section{F. Establish Successful Measures to Assess the Effectiveness of AMTs}

AMTs can provide a whole host of benefits to adopting companies. These benefits are tangible such as inventory savings, less floor space, improved return on equity (R.O.E) and reduced cost of production. The intangible benefits are enhanced competitive advantage, increased flexibility, improved product quality and quick response to customer demand etc.

Appropriate performance measures should be developed because it is necessary to measure both the intangible and tangible benefits of AMTs in order to justify investments in AMTs and to assess if they are indeed achieving the desired objectives for which they were implemented. Then appropriate decisions may be made by top management on whether to continue implementing AMTs or to discontinue its use.

\section{CONCLUSION}

Seventy seven percent (77\%) of the local companies surveyed utilize AMTs. They have to a great extent impacted the local assembly type industry in Trinidad and Tobago. In the present turbulent times, characterized by intense global competition, trade liberalization, fragmented consumer markets and rapid advancement of manufacturing technology, the survival and success of any manufacturing industry has become heavily dependent on their competitiveness. AMTs have made it possible for the local Assembly Type Industry to successfully compete internationally through the cost effective production of high quality, well designed and customized products that meet international standards and consumer taste. Improved productivity, flexibility, increased job satisfaction and the development and maintenance of sustainable competitive advantages are some of the major impacts of AMTs on the local Assembly Type Industry identified by senior management in this study. The companies also noted that there was still room for improvement and steps such as benchmarking against companies in a similar manufacturing environment, establishing a made in TT campaign and identifying appropriate strategies to use the AMTs more effectively could be taken to improve the output from the factories.

\section{ACKNOWLEDGMENT}

The authors acknowledge all the companies and their employees who contributed to the collection of the data for this work.

\section{REFERENCES}

[1] Advameg, Inc. (n.d.). (March 2012). Encyclopedia of Nations. [Online]. Available:

http://www.nationsencyclopedia.com/economies/Americas/Trinidad-a nd-Tobago.html

[2] F. K. Yamfwa, Improving Manufacturing Performance in LDCs: The Case of Zambia, Eindhoven: University Press Facilities, 2001
[3] G. S. Dangayach and S. G. Deshmukh, "Manufacturing strategy perspective on flexibility," Global Journal of Flexible Systems Management, vol. 2, no. 2, pp. 21-30, 2001.

[4] F. Idris, R. Rejab, and A. Ahmad, "Relationships between investments in advanced manufacturing technology (AMT) and performances: Some emperical evidences," European Journal of Economics, Finance and Administrative Sciences, pp. 68-69, 2008.

[5] S. Kotha and P. M. Swamidass, "Strategy, advanced manufacturing technology and performance: Empirical evidence from U.S. manufacturing firms," Journal of Operations Management, p. 257, pp. 259-260, 2000.

[6] K. A. Ghani and V. Jayabalan, "Advanced manufacturing technology and planned organizational change," The Journal of High Technology Management Research, vol. 11, no. 1, pp. 1-18, 2000.

[7] J. Hynek and V. Janeček, "Justification of investment into advanced manufacturing technology,” International Journal of Circuits, Systems and Signal Processing, p. 282, 2007.

[8] M. Tracey, M. A. Vonderembse, and J. S. Lim, "Manufacturing technology and strategy formulation: Keys to enhancing competitiveness and improving performance," Journal of Operations Management, vol. 17, no. 4, pp. 411-428, 1999.

[9] S. G. da Costa, K. Platts, and A. Fleury, "Advanced manufacturing technology: Defining the object and positioning it as an element of manufacturing strategy," in Proc. International Conference on

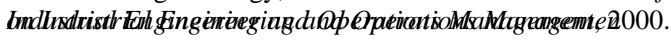

[10] J. R. Meredith and R. McTavish, "Organized manufacturing for superior market performance,” Long Range Planning, vol. 25, no. 6, pp. 63-71, 1992.

[11] R. F. Zammamuto and E. J. O'Connor, "Gaining advanced manufacturing technologies' benefits: The role of organizational design and culture," Academy of Management Review, vol. 17, no. 4, pp. 701-28, 1992.

[12] K. D. Gunawardana and C. Jungthirapanich, "Quantitative measurement of advanced manufacturing technology transfer from foreign-based companies to local companies," working paper, Thailand: Graduate School of Computer and Engineering Management, Assumption University.

[13] S. Saberi, and R. Yusuff, "Advanced manufacturing technology implementation performance: Towards a strategic framework," in Proc. International Conference on Industrial Engineering and Operations Management, pp. 145-147, 2011.

[14] J. W. Jr. Dean and S. A. Snell, "The strategic use of integrated manufacturing: An empirical examination," Strategic Management Journal, vol. 17, no. 6, pp. 459-480, 1996.

[15] J. Hynek, V. Janeček, and L. Svobodová, "Problems associated with investment in advanced manufacturing technology from the management point of view," WSEAS Trans. on Systems, p. 753, 2009.

[16] K. Ramamurthy and W. R. King, "Computer integrated manufacturing: An exploratory study of key organizational barriers," Omega, vol. 20, no. 4, pp. 475-491, 1992.

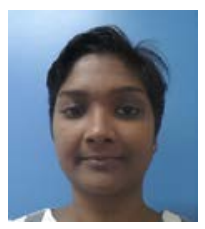

Nadine Sangster was born on October 21, 1977 in Trinidad and Tobago. She received her $\mathrm{PhD}$ in mechanical engineering from The University of the West Indies in 2008. She is an assistant professor in the Design and Manufacturing Unit at The University of Trinidad and Tobago, O'Meara Campus. Her research interests are fuzzy logic and its application to complex plants and the use of smart technologies in agriculture and mechatronics with an emphasis on advanced manufacturing technologies.

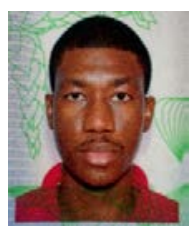

Rondell Duke was born on September 19, 1985. He received his BASc in manufacturing and design engineering from the University of Trinidad and Tobago in 2013.

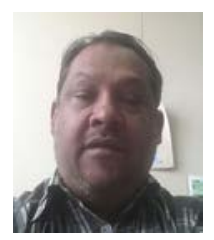

Terrence Lalla was born on May 25, 1961 in Trinidad and Tobago. He received his $\mathrm{PhD}$ in mechanical engineering from the University of the West Indies. He is a lecturer in the Department of Mechanical and Manufacturing Engineering at the University of the West Indies (UWI), St. Augustine. His areas of research are engineering management, quality assurance, and sustainable engineering. 


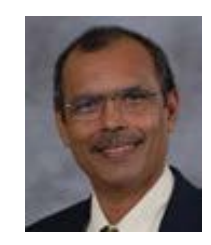

Prakash Persad was born on October 19, 1954 in Trinidad and Tobago. He received his $\mathrm{PhD}$ in mechanical engineering from the University of the West Indies in 1981. He is currently the professor of mechatronics and the programme professor of the Design and Manufacturing Engineering Unit at the University of Trinidad and Tobago. His research interests are in the areas of artificial intelligence, wave powered devices, entertainment, cultural and sporting robotics and the synergy between science and religion.

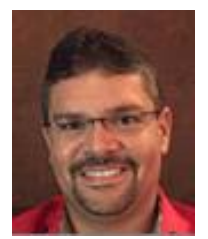

Aaron Ameerali was born on July 4, 1978 in Trinidad and Tobago. He received his MPhil in mechanical engineering from the University of the West Indies in 2004. He is a senior instructor in the Design and Manufacturing Unit at The University of Trinidad and Tobago, O’Meara Campus. He is currently pursuing a Ph.D. in the area of "Developing a robotic device for applications in the manufacture of musical instruments in the idiophone class." His research interests include mechatronics, innovative manufacturing technologies, ergonomics and rapid prototyping. 